\title{
Identification of asymptomatic type 2 diabetes mellitus patients with a low, intermediate and high risk of ischaemic heart disease: is there an algorithm?
}

\author{
M. K. Poulsen • J. E. Henriksen • W. Vach • J. Dahl • \\ J. E. Møller • A. Johansen • O. Gerke • T. Haghfelt • \\ P. F. Høilund-Carlsen $\cdot$ H. Beck-Nielsen
}

Received: 30 July 2009 /Accepted: 2 December 2009 /Published online: 14 January 2010

(C) Springer-Verlag 2010

\begin{abstract}
Aims/hypothesis The leading cause of death in type 2 diabetes is cardiovascular disease (CVD). We examined the prevalence of myocardial ischaemia in type 2 diabetes patients and tried to establish an algorithm to identify patients with a high risk of ischaemic heart disease.

Methods Type 2 diabetes patients who had no known or suspected CVD, and had been referred consecutively to a diabetes clinic for the first time $(n=305$; age $58.6 \pm 11.3$ years; diabetes duration $4.5 \pm 5.3$ years) were screened for myocardial ischaemia using myocardial perfusion scintigraphy (MPS).

Results The univariate predictors of myocardial ischaemia were: atypical or typical angina pectoris, two or more
\end{abstract}

M. K. Poulsen $(\varangle) \cdot$ J. E. Henriksen $\cdot$ H. Beck-Nielsen Department of Endocrinology, Odense University Hospital, Kløvervænget 6, 5th floor, 5000 Odense C, Denmark

e-mail: doc_mkp@hotmail.com.dk

A. Johansen · P. F. Høilund-Carlsen

Department of Nuclear Medicine, Odense University Hospital,

Odense, Denmark

J. Dahl $\cdot$ T. Haghfelt

Department of Cardiology, Odense University Hospital,

Odense, Denmark

\section{J. E. Møller}

Department of Cardiology, Copenhagen University Hospital, Rigshospitalet, University of Copenhagen,

Copenhagen, Denmark

W. Vach $\cdot$ O. Gerke

Department of Statistics, University of Southern Denmark,

Copenhagen, Denmark

traditional risk factors for CVD, BMI $>32 \mathrm{~kg} / \mathrm{m}^{2}$, systolic blood pressure $>140 \mathrm{mmHg}, \mathrm{HbA}_{1 \mathrm{c}}>8.5 \%$, high-sensitivity C-reactive protein $>4.0 \mathrm{mg} / \mathrm{l}$, N-terminal pro-brain natriuretic peptide $>300 \mathrm{pg} / \mathrm{ml}$, left atrial volume index $>32 \mathrm{ml} /$ $\mathrm{m}^{2}$, left ventricular ejection fraction $<50 \%$, and carotid and peripheral arterial disease. The algorithm identified low $(n=$ $96)$, intermediate $(n=65)$ and high risk groups $(n=115)$, in which the prevalence of myocardial ischaemia was $15 \%$, $23 \%$ and $43 \%$, respectively. Overall the algorithm reduced the number of patients referred to MPS from 305 to 144 . However, the sensitivity and specificity of the algorithm was just $68 \%$ and $62 \%$, respectively.

Conclusions/interpretation Our algorithm was able to stratify which patients had a low, intermediate or high risk of myocardial ischaemia based on MPS. However, the algorithm had low sensitivity and specificity, combined with high cost and time requirements.

Trial registration: clinicaltrials.gov NCT00298844

Funding: The study was funded by the Danish Cardiovascular Research Academy (DaCRA), The Danish Diabetes Association and The Danish Heart Foundation.

Keywords Ankle-toe strain gauge technique $\cdot$ B-mode ultrasound scans of carotid arteries · Echocardiography . Myocardial perfusion scintigraphy · Type 2 diabetes mellitus

$\begin{array}{ll}\text { Abbreviations } \\ \text { ADA } & \text { American Diabetes Association } \\ \text { CHD }_{10 \text { year }} & 10 \text { year risk of developing CHD } \\ \text { CVD } & \text { Cardiovascular disease } \\ \text { DIAD } & \begin{array}{l}\text { Detection of silent myocardial } \\ \text { Ischaemia in Asymptomatic Diabetics }\end{array} \\ \text { FRS } & \text { Framingham Risk Score }\end{array}$

Abbreviations 


$\begin{array}{ll}\text { hs-CRP } & \text { High-sensitivity C-reactive protein } \\ \text { LVEF } & \text { Left ventricular ejection fraction } \\ \text { MPS } & \text { Myocardial perfusion scintigraphy } \\ \text { NT-proBNP } & \text { N-terminal pro-brain natriuretic peptide } \\ \text { PAD } & \text { Peripheral arterial disease } \\ \text { RF }_{\text {CVD }} & \begin{array}{l}\text { Cardiovascular risk factors beside } \\ \text { diabetes mellitus }\end{array} \\ \text { ROC } & \text { Receiver operating curve } \\ \text { UKPDS-RS } & \text { UKPDS Risk Engine (version 2.0) score }\end{array}$

\section{Introduction}

The leading cause of death in patients with type 2 diabetes mellitus is cardiovascular disease (CVD) [1-3], which accounts for 50 to $75 \%$ of all deaths $[2,4,5]$. It has been demonstrated that type 2 diabetes patients without prior myocardial infarction have the same probability of cardiac death as patients with prior myocardial infarction but without diabetes [2].

In recent years, many studies have demonstrated that ischaemic heart disease is rather common in type 2 diabetes patients. Thus, the Detection of silent myocardial Ischaemia in Asymptomatic Diabetics (DIAD) study, a multi-centre study of asymptomatic type 2 diabetes patients, performed myocardial perfusion scintigraphy (MPS) and found a prevalence of myocardial ischaemia of $22 \%$ [6]. Other prospective studies using MPS have found a generally high prevalence among asymptomatic type 2 diabetes patients, although prevalence varied from $6 \%$ to $56 \%$ [6-16]. Several studies have used different algorithms to identify type 2 diabetes patients who should or should not be referred to MPS. These algorithms have been based on numbers of CVD risk factors, results of exercise electrocardiography or coronary artery calcium score measurements [7$12,15,16]$. However, so far no generally accepted algorithm has been established.

In a previous publication, we investigated the prevalence of and inter-relationship between myocardial ischaemia and both carotid and peripheral arterial disease (PAD) in a population of well-characterised type 2 diabetes patients, who had no known or suspected CVD and had been referred to a diabetes clinic for the first time [17]. In the present study of the same patients, we wanted to establish an algorithm to discriminate between type 2 diabetes patients with a low, intermediate or high risk of myocardial ischaemia based on MPS. In the attempt to identify these groups, we used clinical and laboratory variables, as well as more sophisticated measurements, e.g. echocardiography, B-mode ultrasound scans of the carotid arteries, and ankle and toe strain gauge technique.

\section{Methods}

Population We consecutively evaluated all 753 type 2 diabetes patients referred to the Diabetes Clinic at Odense University Hospital, Denmark from January 2006 to December 2007; 305 of the patients evaluated met the inclusion and exclusion criteria as previously reported [17].

The study was carried out according to Good Clinical Practice, followed the Helsinki II Declaration, and was approved by the Regional Ethics Committee and registered at www.clinicaltrials.gov. All participants gave written, informed consent.

Each patient underwent a single-day structured examination programme including history recording and a cardiovascular risk factor evaluation. Traditional cardiovascular risk factors besides diabetes mellitus $\left(\mathrm{RF}_{\mathrm{CVD}}\right)$ were: family history of CVD (defined as CVD either in male first-degree relative $<55$ years or in female firstdegree relative $<65$ years), current smoker and a medical history of hypertension or hypercholesterolaemia. Chest discomfort was classified according to the ACC/AHAguidelines [18].

High-sensitivity C-reactive protein (hs-CRP) was determined with a particle immunoassay rate method (IMMAGE; Beckman Coulter, Fullerton, CA, USA). Plasma N-terminal pro-brain natriuretic peptide (NT-proBNP) was determined using a proBNP immunoassay (ELECSYS; Roche Diagnostics, Mannheim, Germany). Finally, the patients were screened by MPS, echocardiography, B-mode ultrasound scans of the carotid arteries, ankle and toe systolic blood pressure measurements, and the 1 point ${ }^{51} \mathrm{Cr}$-EDTA clearance procedure [19].

MPS The MPS examinations were performed using stress ECG-gated ${ }^{99 \mathrm{~m}} \mathrm{Tc}$ MPS according to standards of the American Society of Nuclear Cardiology using ECGgated single photon emission computed tomography [20]. The MPS protocol used in the present population has been published previously [17]. In brief, whenever a potential stress-induced perfusion defect was observed, an additional rest study was carried out the next day to evaluate the degree of reversibility. A semi-quantitative visual interpretation was made by means of short axis, horizontal and vertical long axis myocardial tomograms and a 20 -segment model. All images were analysed by two experts (A. Johansen, P. F. Høilund-Carlsen), who were blinded to all other data and each other, and a summed stress score was calculated. Myocardial ischaemia was defined as a regional perfusion abnormality with a total summed stress score $\geq 4$ and at least one segment having a summed stress score $\geq 2$. Final interpretation and overall diagnosis were obtained by consensus. 
Echocardiography The echocardiograms were performed on a medical ultrasound machine (2.5 $\mathrm{MHz}$ transducer) (Vivid 5; GE, Horten, Norway) and stored digitally for later blinded analysis using EchoPac version 7.0, PC-08 (GE). In brief, left ventricular systolic function was assessed using the biplane Simpson modified method [21]. Left ventricular systolic dysfunction was defined as left ventricular ejection fraction (LVEF) $<50 \%$.

Left atrial volume index was estimated by the biplane area-length method, using measurements at the apical fourand two-chamber views at end-systole (maximum left atrium size) and divided by body surface area [21]. Left atrium volume index was considered moderate or severely increased, if greater than $32 \mathrm{ml} / \mathrm{m}^{2}$ [21].

B-mode ultrasound scans of the carotid arteries Carotid intima-media thickness was measured semi-automatically as the mean of a minimum of 200 measurements per location site (the bulbus region and the proximal end of the common carotid artery) from digitally stored images created using B-mode ultrasound scans (10-MHz linear transducer) of the posterior wall bilaterally at end-diastole. Each image was also investigated for plaques using the ARIC-study plaque definition [22]. Carotid arterial disease was defined as carotid intima-media thickness $>1.00 \mathrm{~mm}$ [23-25] and/ or the presence of a plaque at any carotid location.

Ankle and toe systolic blood pressure measurements These measurements were performed using the strain gauge technique [26]. All participants rested for $20 \mathrm{~min}$ in the supine position before cuffs were placed around the ankles (cuff width $12.0 \mathrm{~cm}$ ) and proximal phalanges of the big toe (cuff width $2.5 \mathrm{~cm}$ ). Strain gauges were placed around the distal phalanges of the big toe. Duplicate measurements of ankle and toe systolic blood pressures were obtained. Arm systolic and diastolic blood pressure was measured. The ankle-brachial index and toe systolic blood pressure index were calculated as the systolic blood pressure at each level, respectively, divided by the arm systolic blood pressure. PAD was defined as ankle-brachial index $<0.90$ and/or toe systolic blood pressure index $<0.64$ [27].

Risk scores The UKPDS Risk Engine (version 2.0) score (UKPDS-RS) [28] and the Framingham Risk Score (FRS) [29] were applied separately in the present study population, and the 10 year risk of developing $\mathrm{CHD}\left(\mathrm{CHD}_{10 \text { year }}\right)$ was obtained.

Statistical analysis Continuous variables are presented as mean and standard deviations, and categorical variables as numbers and percentages with 95\% CIs. We used Student's $t$ test to test for differences between independent continuous variables. Due to a non-Gaussian distribution of hs-CRP and NT-proBNP, these variables are presented as median and interquartile range, and the Mann-Whitney test was used to compare groups. Univariate logistic regression analysis was performed using myocardial ischaemia as outcome variable. The co-variables used in the univariate logistic regression analysis were predefined clinical and laboratory variables (clinical predictors) that had been identified previously as possible predictors of myocardial ischaemia. Based on the univariate logistic regression analysis, we selected a baseline model of significant predictors, which defines the start point (Model 1). Next, we added the sophisticated predictors, i.e. echocardiography variables (LVEF $<50 \%$ and left atrium volume index $>32 \mathrm{ml} / \mathrm{m}^{2}$ ), and both carotid artery disease and PAD to the co-variables in Model 1 and performed a multivariate logistic regression analysis (Model 2). The clinical and sophisticated predictors used in the multivariate logistic regression analysis were all associated with myocardial ischaemia at the $10 \%$ significance level in univariate logistic regression analysis. Results are reported as OR with 95\% CI and $p$ values. For each model, the AUC under the receiver operating curve (ROC) was calculated. The ROCs for Model 1 and 2 were drawn. A $p$ value $<0.05$ was considered statistically significant, unless otherwise stated. STATA, version 9.2 (StataCorp LP, College Station, TX, USA) was used for calculations.

\section{Results}

Characteristics of the type 2 diabetes patients are presented in Table 1.

Predictors of myocardial ischaemia The clinical and laboratory variables (clinical predictors) analysed were predefined well-known predictors of ischaemic heart disease. These clinical predictors were thought to present baseline variables that could easily be obtained, enabling low-cost risk stratification. In the univariate logistic regression analysis, the co-variables associated with the outcome variable myocardial ischaemia on MPS were: atypical or typical angina pectoris, $\mathrm{RF}_{\mathrm{CVD}} \geq 2, \mathrm{BMI}>32 \mathrm{~kg}$ / $\mathrm{m}^{2}$, systolic blood pressure $>140 \mathrm{mmHg}, \mathrm{HbA}_{1 \mathrm{c}}>8.5 \%$, hsCRP $>4.0 \mathrm{mg} / 1$ and NT-proBNP $>300 \mathrm{pg} / \mathrm{ml}$ (Table 2).

The AUC ROC was increased from 0.69 to 0.76 from Model 1 to 2 (Table 3, Fig. 1). The co-variables that were statistically significant in Model 2 were BMI $>32 \mathrm{~kg} / \mathrm{m}^{2}$, $\mathrm{HbA}_{1 \mathrm{c}}>8.5 \%$, left atrium volume index $>32 \mathrm{ml} / \mathrm{m}^{2}$, LVEF $<50 \%$ and PAD (Table 3 ). The addition of the sophisticated measurements increased the AUC ROC and each measurement (except for carotid arterial disease) was significantly associated with myocardial ischaemia. 
Table 1 Demographic characteristics
Data are presented as means \pm $\mathrm{SD}$, median (interquartile range) or $n(\%)$

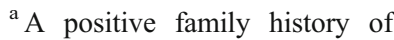
CVD defined as CVD either in male first-degree relative aged $<55$ years or in female firstdegree relative aged $<65$ years

${ }^{\mathrm{b}}$ A medical history of hypertension or hypercholesterolaemia, respectively

${ }^{\mathrm{c}}$ Tested with Mann-Whitney non-parametric test

DPP-IV, dipeptidyl peptidase IV inhibitor treatment

\begin{tabular}{|c|c|c|c|}
\hline Characteristic & $\begin{array}{l}\text { No myocardial } \\
\text { ischaemia }\end{array}$ & $\begin{array}{l}\text { Myocardial } \\
\text { ischaemia }\end{array}$ & $p$ value \\
\hline$n$ & 213 & 92 & \\
\hline Age (years) & $59.0 \pm 11.2$ & $57.5 \pm 11.7$ & NS \\
\hline Male sex, $n(\%)$ & $115(54)$ & $51(55)$ & NS \\
\hline \multicolumn{4}{|l|}{ Diabetes related variables } \\
\hline Diabetes duration (years) & $4.8 \pm 5.5$ & $3.7 \pm 4.8$ & NS \\
\hline BMI $\left(\mathrm{kg} / \mathrm{m}^{2}\right)$ & $31.5 \pm 5.3$ & $33.9 \pm 6.7$ & 0.001 \\
\hline Systolic BP (mmHg) & $137.6 \pm 18.1$ & $141.1 \pm 18.0$ & NS \\
\hline Diastolic BP (mmHg) & $78.9 \pm 11.5$ & $80.8 \pm 9.5$ & NS \\
\hline \multicolumn{4}{|l|}{ Risk factors for CVD, $n(\%)$} \\
\hline Family history of CVD ${ }^{\mathrm{a}}$ & $37(17)$ & $20(22)$ & NS \\
\hline Hypertension $^{\mathrm{b}}$ & $135(63)$ & $61(66)$ & NS \\
\hline Hypercholesterolaemia $^{\mathrm{b}}$ & $131(62)$ & $62(67)$ & NS \\
\hline Current smoker & $55(26)$ & $26(28)$ & NS \\
\hline \multicolumn{4}{|l|}{ Angina pectoris, $n(\%)$} \\
\hline None & $174(82)$ & $62(67)$ & 0.006 \\
\hline Non-cardiac chest pain & $24(11)$ & $16(17)$ & NS \\
\hline Atypical angina pectoris & $8(4)$ & $9(10)$ & 0.035 \\
\hline Typical angina pectoris & $7(3)$ & $5(5)$ & NS \\
\hline \multicolumn{4}{|l|}{ Glucose-lowering medical treatment, $n(\%)$} \\
\hline No glucose-lowering agents & $18(20)$ & $47(22)$ & NS \\
\hline Metformin & $58(63)$ & $131(62)$ & NS \\
\hline Rosiglitazone & $5(5)$ & $14(7)$ & NS \\
\hline DPP-IV inhibitor & $2(2)$ & $3(1)$ & NS \\
\hline Sulfonylurea & $21(23)$ & $55(26)$ & NS \\
\hline Insulin & $23(25)$ & $50(23)$ & NS \\
\hline \multicolumn{4}{|l|}{ Blood samples } \\
\hline Fasting plasma glucose (mmol/l) & $8.6 \pm 2.4$ & $8.8 \pm 2.7$ & NS \\
\hline $\mathrm{HbA}_{1 \mathrm{c}}(\%)$ & $7.2 \pm 1.2$ & $7.5 \pm 1.4$ & NS \\
\hline Fasting C-peptide (pmol/l) & $1103 \pm 603$ & $1246 \pm 723$ & NS \\
\hline Fasting insulin (pmol/l) & $100 \pm 93$ & $120 \pm 124$ & NS \\
\hline Total cholesterol $(\mathrm{mmol} / \mathrm{l})$ & $4.4 \pm 1.0$ & $4.3 \pm 1.0$ & NS \\
\hline LDL-cholesterol (mmol/l) & $2.2 \pm 0.8$ & $2.2 \pm 0.8$ & NS \\
\hline HDL-cholesterol (mmol/1) & $1.30 \pm 0.35$ & $1.23 \pm 0.32$ & NS \\
\hline hs-CRP $\left(\mathrm{mg} / \mathrm{l}^{\mathrm{c}}\right.$ & $5.3 \pm 7.1$ & $6.4 \pm 9.4$ & NS \\
\hline NT-proBNP $(\mathrm{pg} / \mathrm{ml})^{\mathrm{c}}$ & $124 \pm 252$ & $154 \pm 317$ & NS \\
\hline \multicolumn{4}{|l|}{ Echocardiography, $n(\%)$} \\
\hline Left atrium volume index $>32 \mathrm{ml} / \mathrm{m}^{2}$ & $56(26)$ & $43(47)$ & $<0.001$ \\
\hline LVEF $<50 \%$ & $11(5)$ & $16(17)$ & 0.001 \\
\hline \multicolumn{4}{|c|}{ B-mode ultrasound of carotid arteries, $n(\%)$} \\
\hline Carotid arterial disease & $81(38)$ & $48(52)$ & 0.022 \\
\hline \multicolumn{4}{|l|}{ Ankle and toe systolic BP } \\
\hline $\mathrm{PAD}, n(\%)$ & $24(11)$ & $21(23)$ & 0.009 \\
\hline \multicolumn{4}{|l|}{ One-point ${ }^{51} \mathrm{Cr}$-EDTA clearance procedure } \\
\hline GFR $\left(\mathrm{ml} \min ^{-1} \mathrm{~m}^{-2}\right)$ & $87.7 \pm 22.6$ & $93.8 \pm 23.4$ & 0.033 \\
\hline
\end{tabular}

Algorithm for prediction of myocardial ischaemia Figure 2 shows an algorithm that tries to translate the results of our multivariate analyses into a simple clinical prediction rule for selection of patients who should be referred to MPS in the attempt to diagnose myocardial ischaemia. According to American Diabetes Association (ADA) guidelines, type 2 diabetes patients with typical or atypical angina pectoris should be referred for stress testing [1]. These patients were 
Table 2 Univariate clinical and sophisticated predictors of myocardial ischaemia on MPS
Data are presented as OR, 95\% CIs and $p$ values

\begin{tabular}{|c|c|c|c|}
\hline Co-variables & Odds ratio & $95 \% \mathrm{CI}$ & $p$ value \\
\hline \multicolumn{4}{|l|}{ Clinical predictors } \\
\hline Age (years) & 0.99 & $0.97-1.01$ & 0.270 \\
\hline Male sex & 1.06 & $0.65-1.73$ & 0.816 \\
\hline Diabetes duration (years) & 0.96 & $0.91-1.01$ & 0.121 \\
\hline Atypical or typical angina pectoris & 2.37 & $1.09-5.14$ & 0.029 \\
\hline $\mathrm{BMI}>32 \mathrm{~kg} / \mathrm{m}^{2}$ & 2.06 & $1.25-3.38$ & 0.004 \\
\hline Systolic BP $>140 \mathrm{mmHg}$ & 1.61 & $0.98-2.64$ & 0.058 \\
\hline Diastolic BP $>90 \mathrm{mmHg}$ & 1.14 & $0.58-2.24$ & 0.635 \\
\hline Family history of CVD & 1.32 & $0.72-2.43$ & 0.370 \\
\hline Hypertension & 1.14 & $0.68-1.90$ & 0.625 \\
\hline Hypercholesterolaemia & 1.29 & $0.77-2.17$ & 0.328 \\
\hline Current smoker & 1.13 & $0.65-1.96$ & 0.658 \\
\hline $\mathrm{RF}_{\mathrm{CVD}} \geq 2$ & 1.68 & $1.00-2.82$ & 0.048 \\
\hline $\mathrm{HbA}_{1 \mathrm{c}}>8.5 \%$ & 2.22 & $1.17-4.22$ & 0.015 \\
\hline Total cholesterol $>5 \mathrm{mmol} / \mathrm{l}$ & 0.81 & $0.43-1.52$ & 0.511 \\
\hline LDL-cholesterol $>2.5 \mathrm{mmol} / 1$ & 0.78 & $0.45-1.35$ & 0.371 \\
\hline HDL-cholesterol $<0.9 \mathrm{mmol} / \mathrm{l}$ & 1.25 & $0.54-2.92$ & 0.606 \\
\hline hs-CRP $>4.0 \mathrm{mg} / 1$ & 2.05 & $1.24-3.36$ & 0.005 \\
\hline NT-proBNP $>300 \mathrm{pg} / \mathrm{ml}$ & 2.07 & $0.97-4.40$ & 0.059 \\
\hline \multicolumn{4}{|l|}{ Sophisticated predictors } \\
\hline GFR $<60 \mathrm{ml} \min ^{-1} \mathrm{~m}^{-2}$ & 0.68 & $0.28-1.65$ & 0.393 \\
\hline Left atrium volume index $>32 \mathrm{ml} / \mathrm{m}^{2}$ & 2.46 & $1.48-4.10$ & 0.001 \\
\hline LVEF $<50 \%$ & 3.87 & $1.72-8.71$ & 0.001 \\
\hline Carotid arterial disease & 1.78 & $1.08-2.91$ & 0.022 \\
\hline $\mathrm{PAD}$ & 2.33 & $1.22-4.44$ & 0.010 \\
\hline
\end{tabular}

therefore selected and sent directly to MPS in our algorithm. Patients without typical or atypical angina pectoris were then screened in a first step using six clinical predictors. All clinical predictors that were significant in the univariate analysis had ORs of almost similar magnitude; hence, we simply counted the number of predictors present (Table 3). If two or more of these were fulfilled, the patients were examined by (1) echocardiography to assess left atrium volume index and LVEF; (2) B-mode ultrasound scans of the carotid arteries to evaluate whether carotid arterial disease was present; and (3) ankle and toe systolic blood pressure measurements to evaluate if PAD was present. Again, in this second step, we simply counted the number of predictors present, as all four predictors had ORs of almost similar magnitude in Model 2 (Table 3). With this algorithm, 29 patients with typical or atypical angina pectoris were sent directly to MPS, of whom $48 \%$ had myocardial ischaemia based on MPS. Of the remaining 276 patients, 180 fulfilled two or more of the remaining six clinical predictors, whereas 96 patients did not. Of the latter 96 patients, $15 \%$ had myocardial ischaemia on MPS, making this a low-risk group. The 180 patients fulfilling two or more of the clinical predictors underwent the sophisticated measurements, of whom 115 fulfilled one or more of the sophisticated predictors. Of these 115 patients, $43 \%$ had myocardial ischaemia, making this a high-risk group. Finally, 23\% of the remaining 65 of the 180 patients who did not fulfil one or more of the sophisticated predictors had myocardial ischaemia, making this an intermediate-risk group.

By introducing the algorithm (Fig. 2), the number of patients who need to be referred to MPS was reduced from $305(100 \%)$ to $144(47 \%)$ patients. The sensitivity and specificity of the algorithm in Fig. 2 to detect myocardial ischaemia were $68 \%$ and $62 \%$, respectively.

Risk scores In the present study population, the UKPDS-RS $\mathrm{CHD}_{10 \text { year }}$ and the FRS $\mathrm{CHD}_{10 \text { year }}$ were on average $15.0 \pm$ $11.1 \%$ and $14.9 \pm 9.4 \%$, respectively. In patients with myocardial ischaemia on MPS, the UKPDS-RS $\mathrm{CHD}_{10 \text { year }}$ was $15.6 \pm 11.5 \%$ vs $14.8 \pm 10.9 \%$ for those without $(p=0.54)$. With respect to the FRS $\mathrm{CHD}_{10 y e a r}$ it was $15.5 \pm 10.0 \%$ vs $14.7 \pm 9.2 \%(p=0.46)$. Both UKPDS-RS and FRS CHD 10 year were further used to stratify which patients should be referred to MPS in the present study. Three UKPDS-RS and FRS $\mathrm{CHD}_{10 y e a r}$ levels were applied separately to investigate which 
Table 3 Models predicting myocardial ischaemia
Data are presented as ORs, $95 \%$ CIs, $p$ values and AUC ROC

\begin{tabular}{|c|c|c|c|c|}
\hline Co-variables & Odds ratio & $95 \% \mathrm{CI}$ & $p$ value & AUC ROC \\
\hline Model 1 & & & & 0.69 \\
\hline Atypical or typical angina pectoris & 2.06 & $0.91-4.67$ & 0.084 & \\
\hline $\mathrm{RF}_{\mathrm{CVD}} \geq 2$ & 1.47 & $0.84-2.51$ & 0.177 & \\
\hline BMI $>32 \mathrm{~kg} / \mathrm{m}^{2}$ & 1.78 & $1.04-3.07$ & 0.036 & \\
\hline Systolic BP $>140 \mathrm{mmHg}$ & 1.22 & $0.72-2.07$ & 0.468 & \\
\hline $\mathrm{HbA}_{1 \mathrm{c}}>8.5 \%$ & 2.07 & $1.06-4.02$ & 0.032 & \\
\hline hs-CRP $>4.0 \quad \mathrm{mg} / 1$ & 1.78 & $1.05-3.03$ & 0.033 & \\
\hline NT-proBNP $>300 \mathrm{pg} / \mathrm{ml}$ & 2.08 & $0.95-4.57$ & 0.069 & \\
\hline Model 2 & & & & 0.76 \\
\hline Atypical or typical angina pectoris & 2.20 & $0.91-5.35$ & 0.081 & \\
\hline $\mathrm{RF}_{\mathrm{CVD}} \geq 2$ & 1.27 & $0.71-2.26$ & 0.421 & \\
\hline BMI $>32 \mathrm{~kg} / \mathrm{m}^{2}$ & 2.33 & $1.29-4.24$ & 0.005 & \\
\hline Systolic BP $>140 \mathrm{mmHg}$ & 1.03 & $0.59-1.80$ & 0.931 & \\
\hline $\mathrm{HbA}_{1 \mathrm{c}}>8.5 \%$ & 2.20 & $1.08-4.49$ & 0.030 & \\
\hline hs-CRP $>4.0 \quad \mathrm{mg} / 1$ & 1.83 & $1.04-3.22$ & 0.035 & \\
\hline NT-proBNP $>300 \quad \mathrm{pg} / \mathrm{ml}$ & 0.94 & $0.38-2.34$ & 0.888 & \\
\hline Left atrium volume index $>32 \mathrm{ml} / \mathrm{m}^{2}$ & 2.16 & $1.19-3.94$ & 0.012 & \\
\hline LVEF $<50 \%$ & 3.41 & $1.36-8.53$ & 0.009 & \\
\hline Carotid arterial disease & 1.47 & $0.84-2.59$ & 0.179 & \\
\hline $\mathrm{PAD}$ & 2.23 & $1.05-4.78$ & 0.038 & \\
\hline
\end{tabular}

levels would be optimal: these were the 5\%,10\% and 15\% levels, respectively. As mentioned above, patients with typical or atypical angina pectoris were not included in the analysis, since these should be referred directly to MPS
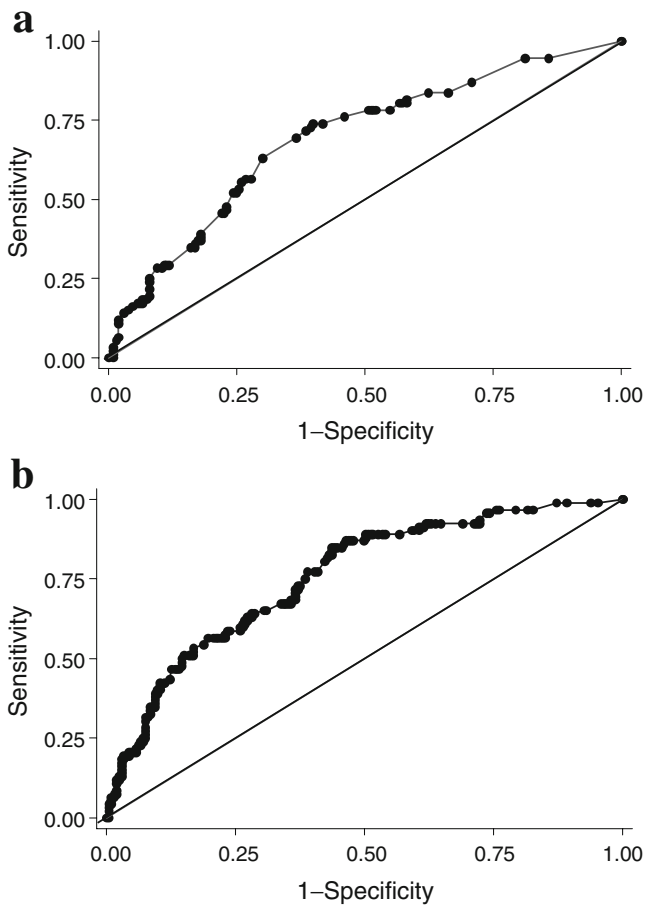

Fig. 1 The ROC and AUC ROC for (a) Model 1 and (b) Model 2, respectively. AUC ROC (a): 0.69; (b): 0.76 according to ADA guidelines [1]. In the present study population of patients without typical or atypical angina pectoris $(n=276)$, stratifying at the 5\% level for UKPDS-RS $\mathrm{CHD}_{10 y e a r}$ and FRS $\mathrm{CHD}_{10 y e a r}$ demonstrated that $38 \%$ and $36 \%$ of patients with a risk $\leq 5 \%$ had myocardial ischaemia on MPS, respectively. Stratifying at the $10 \%$ level for both risk score models, we found that $28 \%$ and $25 \%$ of patients with a risk $\leq 10 \%$ had myocardial ischaemia, respectively. Finally, when stratifying at the $15 \%$ level for both risk score models, we showed that $28 \%$ and $29 \%$ of patients with a risk $\leq 15 \%$ had myocardial ischaemia, respectively. Hence, in none of the three groups $(\leq 5 \%, \leq 10 \%$ and $\leq 15 \%)$ was the prevalence of myocardial ischaemia using both UKPDS-RS and FRS $\mathrm{CHD}_{10 \text { year }}$ lower than in all 276 patients, except for FRS $\mathrm{CHD}_{10 \text { year }} \leq 10 \%$, where the prevalence of myocardial ischaemia was $25 \%$ compared with $28 \%$ in all 276 patients.

\section{Discussion}

In the present study we introduced an algorithm for identification of myocardial ischaemia on MPS in type 2 diabetes patients. This algorithm can identify patients with a low, intermediate or high risk of myocardial ischaemia using both simple clinical and more sophisticated measurements.

From the multivariate models, addition of the co-variables left atrium volume index $>32 \mathrm{ml} / \mathrm{m}^{2}$, LVEF $<50 \%$, carotid artery disease and PAD to the clinical predictors increased 


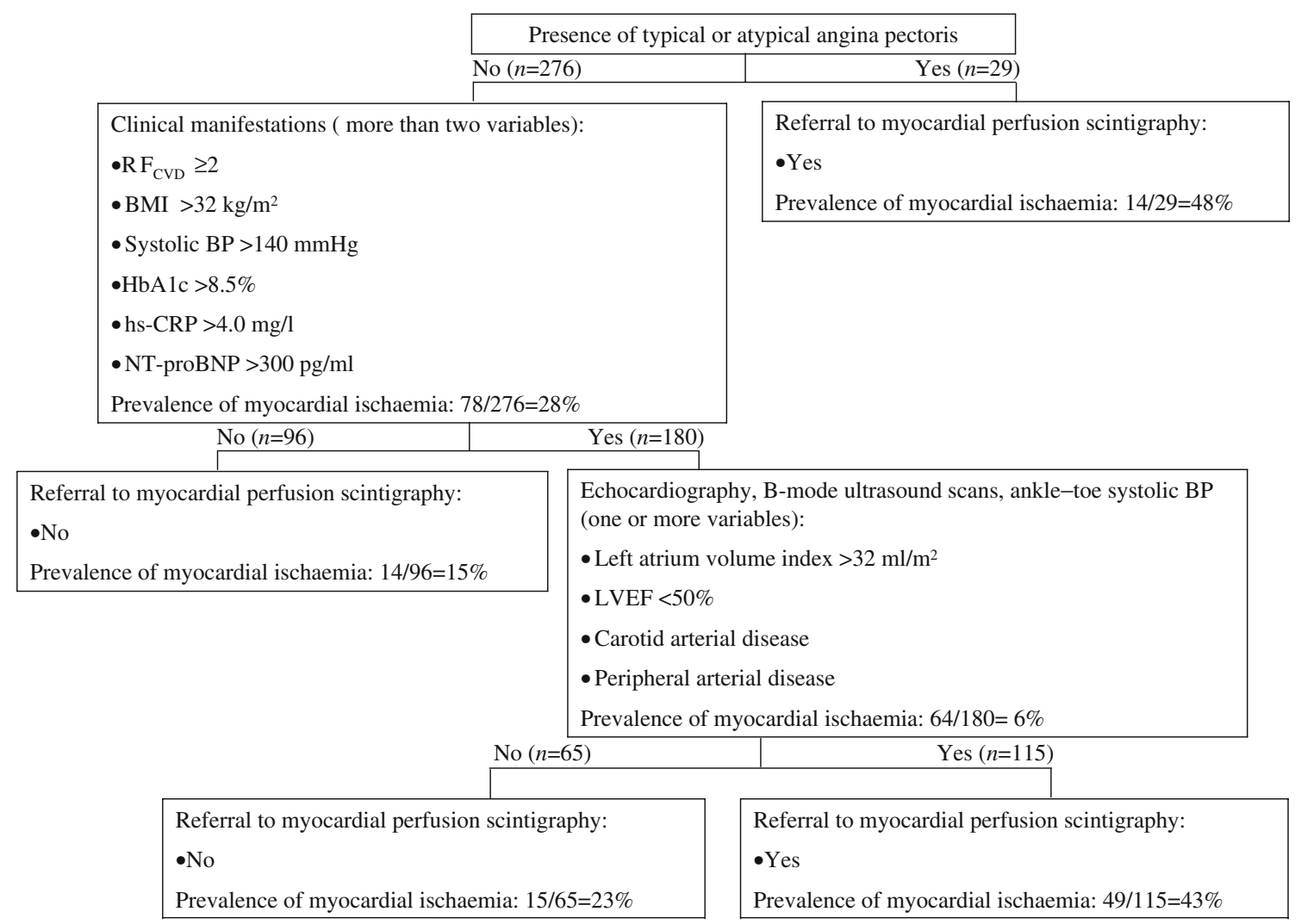

Fig. 2 Algorithm: how to identify type 2 diabetes patients needing referral to MPS. Prevalence of myocardial ischaemia = number of patients with myocardial ischaemia on MPS/number of patients screened in each step of the algorithm

the AUC ROC from Model 1 to 2 (Table 3). The covariables left atrium volume index $>32 \mathrm{ml} / \mathrm{m}^{2}, \mathrm{LVEF}<50 \%$ and PAD all had significant ORs. Thus, the addition of each of these variables increased the explanatory power of the model.

Inspecting the ROC of Model 2, the model with the highest AUC ROC value suggested that a sensitivity and specificity in the magnitude of $70 \%$ and $65 \%$, respectively should be possible (Fig. 1). The sensitivity and specificity obtained from the ROC curve of Model 2 is based on the optimal combination of the co-variables selected in the present study and should hence be considered to be too optimistic. The algorithm presented in Fig. 2 had 68\% sensitivity and 62\% specificity. These values were rather close to the optimal sensitivity and specificity obtained from the ROC of Model 2 , the slight decrease being the price we paid for seeking to find a simple clinical predictive rule. In particular, we forced the seven clinical predictors into the algorithm before the more sophisticated predictors were introduced, since this approach made sense from a clinical point of view. Therefore, in the present algorithm only patients with intermediate or high risk of myocardial ischaemia were investigated with the sophisticated measurements. The algorithm identified a low-, intermediate- and high-risk group, in which the prevalence of myocardial ischaemia was $15 \%, 23 \%$ and $43 \%$, respectively. Overall, the algorithm reduced the number of patients referred to MPS from 305 $(100 \%)$ to $144(47 \%)$. However, the algorithm also had a rather low sensitivity and specificity, resulting in many false negative results $(n=29)$ and meaning that the sophisticated measurements in combination were not efficient enough to identify all patients with myocardial ischaemia on MPS and to classify these into the high-risk group.

In the present study, we also calculated the 10 year risk of suffering from CHD using both the UKPDS-RS [28] and FRS [29] $\mathrm{CHD}_{10 \text { year }}$ By introducing these two risk score models separately at the $5 \%, 10 \%$ or $15 \%$ levels, three lowrisk groups for each model were created containing from 42 to 165 patients of the 276 patients examined. The size of each of these low-risk groups seemed reasonable, so we did not test other levels below $5 \%$ or above $15 \%$. However, the groups created by the two risk score methods (UKPDS-RS, FRS) actually failed to identify low-risk patients, as each of these groups had a prevalence of myocardial ischaemia at least as high as the entire group of patients without typical or atypical angina pectoris; an exception was the FRS $\mathrm{CHD}_{10 \text { year }} \leq 10 \%$, which was almost the same as the entire group $(25 \%$ vs $28 \%)$. It has to be kept in mind that the UKPDS-RS and FRS CHD 10 year predict risk of developing CHD and not risk of having myocardial ischaemia on MPS, 
as our algorithm was constructed to do. Despite this, it is well established that summed stress score on MPS can predict CHD in diabetes patients [30] and therefore diabetes patients with myocardial ischaemia on MPS should be identified by more general tools like the UKPDS-RS [28] and FRS [29] $\mathrm{CHD}_{10 y e a r}$. We did not include age in our algorithm, since it was not significant in the univariate analysis, even though we know from many studies that age is a strong predictor of CVD. This can be explained by selection bias in the present study, since only the elderly without CVD were included. In this respect, it is essential to highlight that algorithms like ours should only be used in populations identical to the population from which the algorithm was derived. In addition, we acknowledge that the very best approach would be to follow-up the entire population and assess the true predictive value of the algorithm for future cardiovascular events. However, these data are not available yet. Finally, it should be mentioned that the sensitivity and specificity of the algorithm is dependent on the prevalence of true positive tests.

Some studies have used modalities like exercise electrocardiography $[8,11]$ or coronary artery calcium score measurements [7] as gatekeepers before referral to MPS. However, none of these studies investigated whether their particular 'gatekeeper' could actually select type 2 diabetes patients who should or should not be referred to MPS, since only patients with abnormal pre-tests were sent to MPS. Our study is the first to try systematically to identify type 2 diabetes patients with a low, intermediate or high risk of myocardial ischaemia on MPS. It is debatable whether our algorithm could become clinically useful. Using it, we were forced to accept a prevalence of myocardial ischaemia up to $15 \%$ in the low-risk group. On the other hand, our algorithm seemed to be close to the optimum obtainable with this set of variables in the present population, as multivariate models did not lead to a clear further improvement according to the ROC of Model 2.

An attempt to answer the question of whether to screen for ischaemic heart disease by MPS or not in asymptomatic type 2 diabetes patients was made in a recent publication of the DIAD study [31]. The authors concluded that screening with MPS was not favourable, since only few patients had moderate to large defects on MPS in combination with the low cardiac event and cardiac mortality rates of the entire population after a follow-up period of $4.8 \pm 0.9$ years. On the other hand, patients with moderate to large perfusion defects at baseline in the DIAD study had a $12 \%$ cardiac event rate during the follow-up period compared with $2 \%$ for patients with a normal MPS. Thus, algorithms like ours, which can select asymptomatic patients with a high risk of myocardial ischaemia on MPS, and especially among those with moderate to large defects, seem warranted as a way of attempting to reduce the number of patients who need to be screened. However, before introducing screening models like the one proposed in the present study, further studies are needed. In particular, the modality used for screening (i.e. MPS) should be associated with an increased risk of future CVD; and more importantly, interventional strategies should be tested in the group of patients with myocardial ischaemia on MPS in order to find out if it is possible to reduce morbidity and mortality rates in these patients.

Study limitations Our study was limited in that 126 of 431 eligible patients refused to participate or did not show up. However, no statistical differences were present between the study group and the non-participants with regard to age and diabetes duration. Despite this, selection bias cannot be ruled out.

A second limitation is that in the present study GFR was significantly higher in patients with myocardial ischaemia on MPS than in those without. Since it is well established that decreased GFR is related to increased risk of cardiovascular events and death in type 2 diabetes patients [32, 33], one cannot help speculating that this difference might at least partly be caused by some selection bias, although unintended.

Conclusions/interpretation The algorithm established in the present study, using both simple clinical and more sophisticated predictors, was able to stratify type 2 diabetes patients according to a low, intermediate or high risk of myocardial ischaemia on MPS. However, it is debatable whether our algorithm could become clinically useful, since its sensitivity and specificity for detection of myocardial ischaemia were rather low in combination with high cost and time requirements.

Acknowledgements Our thanks go to the laboratory technicians: L. Hansen, C. Olsen, P. Hedegaard, I. Knudsen, S. Hold, T. Godskesen and M. Høilund-Carlsen for their effort in the study. The study was funded by the Danish Cardiovascular Research Academy (DaCRA), The Danish Diabetes Association and The Danish Heart Foundation.

Duality of interest The authors declare that there is no duality of interest associated with this manuscript.

\section{References}

1. American Diabetes Association (2005) Standards of medical care in diabetes. Diabetes Care 28(Suppl 1):S4-S36

2. Haffner SM, Lehto S, Ronnemaa T, Pyorala K, Laakso M (1998) Mortality from coronary heart disease in subjects with type 2 diabetes and in nondiabetic subjects with and without prior myocardial infarction. N Engl J Med 339:229-234

3. Kannel WB, McGee DL (1979) Diabetes and cardiovascular disease. The Framingham study. JAMA 241:2035-2038

4. Bonow RO, Bohannon N, Hazzard W (1996) Risk stratification in coronary artery disease and special populations. Am J Med 101:4A17S-4A22S 
5. Schramm TK, Gislason GH, Kober L et al (2008) Diabetes patients requiring glucose-lowering therapy and nondiabetics with a prior myocardial infarction carry the same cardiovascular risk: a population study of 3.3 million people. Circulation 117:1945-1954

6. Wackers FJ, Young LH, Inzucchi SE et al (2004) Detection of silent myocardial ischemia in asymptomatic diabetic subjects: the DIAD study. Diabetes Care 27:1954-1961

7. Anand DV, Lim E, Hopkins D et al (2006) Risk stratification in uncomplicated type 2 diabetes: prospective evaluation of the combined use of coronary artery calcium imaging and selective myocardial perfusion scintigraphy. Eur Heart J 27:713-721

8. No authors listed (1997) Prevalence of unrecognized silent myocardial ischemia and its association with atherosclerotic risk factors in noninsulin-dependent diabetes mellitus. Milan Study on Atherosclerosis and Diabetes (MiSAD) Group. Am J Cardiol 79:134-139

9. Avignon A, Sultan A, Piot C et al (2007) Osteoprotegerin: a novel independent marker for silent myocardial ischemia in asymptomatic diabetic patients. Diabetes Care 30:2934-2939

10. Cosson E, Paycha F, Paries J et al (2004) Detecting silent coronary stenoses and stratifying cardiac risk in patients with diabetes: ECG stress test or exercise myocardial scintigraphy? Diabet Med 21:342-348

11. Gazzaruso C, Garzaniti A, Giordanetti S et al (2002) Assessment of asymptomatic coronary artery disease in apparently uncomplicated type 2 diabetic patients: a role for lipoprotein(a) and apolipoprotein(a) polymorphism. Diabetes Care 25:1418-1424

12. Janand-Delenne B, Savin B, Habib G, Bory M, Vague P, Lassmann-Vague V (1999) Silent myocardial ischemia in patients with diabetes: who to screen. Diabetes Care 22:1396-1400

13. Koistinen MJ (1990) Prevalence of asymptomatic myocardial ischaemia in diabetic subjects. BMJ 301:92-95

14. Scholte AJ, Schuijf JD, Kharagjitsingh AV et al (2008) Different manifestations of coronary artery disease by stress SPECT myocardial perfusion imaging, coronary calcium scoring, and multislice CT coronary angiography in asymptomatic patients with type 2 diabetes mellitus. J Nucl Cardiol 15:503-509

15. Sultan A, Piot C, Mariano-Goulart D et al (2006) Myocardial perfusion imaging and cardiac events in a cohort of asymptomatic patients with diabetes living in southern France. Diabet Med 23:410-418

16. Vanzetto G, Halimi S, Hammoud T et al (1999) Prediction of cardiovascular events in clinically selected high-risk NIDDM patients. Prognostic value of exercise stress test and thallium-201 single-photon emission computed tomography. Diabetes Care 22:19-26

17. Poulsen MK, Henriksen JE, Dahl J et al (2009) Myocardial ischemia, carotid, and peripheral arterial disease and their interrelationship in type 2 diabetes patients. J Nucl Cardiol 16:878-887

18. Gibbons RJ, Chatterjee K, Daley J et al (1999) ACC/AHA/ACPASIM guidelines for the management of patients with chronic stable angina: executive summary and recommendations. A report of the American College of Cardiology/American Heart Association task force on practice guidelines (Committee on Management of Patients with Chronic Stable Angina). Circulation 99:2829-2848
19. Christensen AB, Groth S (1986) Determination of ${ }^{99 m}$ Tc-DTPA clearance by a single plasma sample method. Clin Physiol 6:579 588

20. Klocke FJ, Baird MG, Lorell BH et al (2003) ACC/AHA/ASNC guidelines for the clinical use of cardiac radionuclide imagingexecutive summary: a report of the American College of Cardiology/American Heart Association task force on practice guidelines (ACC/AHA/ASNC Committee to revise the 1995 guidelines for the clinical use of cardiac radionuclide imaging). Circulation 108:1404-1418

21. Lang RM, Bierig M, Devereux RB et al (2006) Recommendations for chamber quantification. Eur J Echocardiogr 7:79-108

22. Li R, Duncan BB, Metcalf PA et al (1994) B-mode-detected carotid artery plaque in a general population. Atherosclerosis Risk in Communities (ARIC) study investigators. Stroke 25:2377-2383

23. Chambless LE, Heiss G, Folsom AR et al (1997) Association of coronary heart disease incidence with carotid arterial wall thickness and major risk factors: the Atherosclerosis Risk in Communities (ARIC) study, 1987-1993. Am J Epidemiol 146:483-494

24. Chambless LE, Folsom AR, Clegg LX et al (2000) Carotid wall thickness is predictive of incident clinical stroke: the Atherosclerosis Risk in Communities (ARIC) study. Am J Epidemiol 151:478-487

25. Salonen JT, Salonen R (1991) Ultrasonographically assessed carotid morphology and the risk of coronary heart disease. Arterioscler Thromb 11:1245-1249

26. Gundersen J (1972) Segmental measurements of systolic blood pressure in the extremities including the thumb and the great toe. Acta Chir Scand Suppl 426:1-90

27. Carter SA, Lezack JD (1971) Digital systolic pressures in the lower limb in arterial disease. Circulation 43:905-914

28. Diabetes Trials Unit, Oxford (2009) UKPDS Risk Engine, version 2.0. Available from www.dtu.ox.ac.uk/riskengine, accessed 28 July 2009

29. Wilson PW, D'Agostino RB, Levy D, Belanger AM, Silbershatz H, Kannel WB (1998) Prediction of coronary heart disease using risk factor categories. Circulation 97:1837-1847

30. Kang X, Berman DS, Lewin HC et al (1999) Incremental prognostic value of myocardial perfusion single photon emission computed tomography in patients with diabetes mellitus. Am Heart J 138:1025-1032

31. Young LH, Wackers FJ, Chyun DA et al (2009) Cardiac outcomes after screening for asymptomatic coronary artery disease in patients with type 2 diabetes: the DIAD study: a randomized controlled trial. JAMA 301:1547-1555

32. Nag S, Bilous R, Kelly W, Jones S, Roper N, Connolly V (2007) All-cause and cardiovascular mortality in diabetic subjects increases significantly with reduced estimated glomerular filtration rate (eGFR): 10 years' data from the South Tees Diabetes Mortality study. Diabet Med 24:10-17

33. Knobler H, Zornitzki T, Vered S et al (2004) Reduced glomerular filtration rate in asymptomatic diabetic patients: predictor of increased risk for cardiac events independent of albuminuria. J Am Coll Cardiol 44:2142-2148 